Article

\title{
Improved Identification and New Records of Dendroctonus Bark Beetles Attacking Pinus contorta in the Subalpine Forest of the Southern Rocky Mountains
}

\author{
Javier E. Mercado
}

Rocky Mountain Research Station, USDA/Forest Service, Fort Collins, CO 80526, USA; javier.mercado@usda.gov

Received: 16 May 2020; Accepted: 3 June 2020; Published: 9 June 2020

\begin{abstract}
Research Highlights: Atypical and poorly understood attacks by Dendroctonus rufipennis (Kirby) to Pinus contorta Doug. ex Loudon were detected in the southern Rocky Mountains (SRM). The phenomenon is confirmed across all examined area. Its reproduction is described for the first time as well as the first attacks of D. adjunctus Blandf. in that host. Improved detection and diagnostics of D. rufipennis will allow a simpler, and efficient identification of the species. It will improve the detection capacity by pest detection specialists and entomologists, which will increase our understanding of the phenomena within and beyond the known range. Background and Objectives: In addition to D. ponderosae Hopk. other Dendroctonus species, sometimes together, attacked P. contorta that grew intermixed with Picea engelmannii in the SRM' subalpine forest. The identification of these beetles was difficult. The goal was to improve the detection and identification of the species from similar Dendroctonus spp. attacking that host and to uncover biological facts about the phenomena. Materials and Methods: Dendroctonus attacking P. contorta were collected along the entire SRM, their attack signs and behavior were recorded. These characteristics were revised from those in the literature and new characters were introduced and tested. Results: The identification of Dendroctonus bark beetles attacking $P$. contorta in the SRM was improved using revised and new characters including attack signs, attack behavior, and adult beetle characters. An improved identification key couplet is presented to effectively distinguish D. murrayanae from D. rufipennis. Conclusions: Simplified insect identifications that are both accessible to users with different levels of expertise and are based on insect characters, their attack pattern, and signs, like the present, improve detection of insects of interest. Efficient insect detections allow a better understanding of the capabilities they have and the impact they cause to the woodland ecosystems we study, protect, and manage around the globe.
\end{abstract}

Keywords: non-host attack; post-epidemic; facilitation; endemic population strategies

\section{Introduction}

In the southern Rocky Mountains (SRM) of Colorado and southern Wyoming, Pinus contorta Douglas (lodgepole pine) grows from 2400 to $3200 \mathrm{~m}$, intermixing with Picea engelmannii Parry ex Engelm (Engelmann spruce) in the subalpine zone, at elevations above $2800 \mathrm{~m}$ [1]. In this temperate mountain forest, native Dendroctonus bark beetles kill trees altering forest structure and species composition. Two Dendroctonus bark beetles attack P. contorta natively, D. ponderosae Hopk. (mountain pine beetle) and D. murrayanae Hopk. (lodgepole pine beetle). The magnitude of the impact on their host is different. For instance, during the most recent epidemic, D. ponderosae killed approximately $60 \%$ of the mature P. contorta within the SRMs [2,3], whereas D. murrayanae was reported affecting only small patches of trees [4]. The disparity of the beetles' impact reflects their different biologies. While $D$. ponderosae attacks all Pinus species in the SRM, D. murrayanae only attacks $P$. contorta. Moreover, 
D. ponderosae occurs throughout the SRMs, while D. murrayanae only occurs above latitude $39.4^{\circ}$, as it appears to be limited to cooler, northern regions [5]. In addition, $P$. engelmannii has a native Dendroctonus enemy, Dendroctonus rufipennis (Kirby) (North American spruce beetle), with D. ponderosae attacking Picea spp. on rare occasions. With reddish elytra that contrasts with a dark brown head and prothorax, adult D. rufipennis and D. murrayanae closely resemble each other in color, but also in size, shape, and other external characters. The two Dendroctonus are also difficult to distinguish behaviorally since they have similar egg galleries, egg placing patterns, and brood aggregation patterns [6]. Therefore, the distinction between the beetle species is usually based on the infested host [5,7]. Dendroctonus rufipennis populations have been irruptive during the last 20 years, killing large numbers of suitable P. engelmannii in the SRM.

In the SRM, subalpine forest coincides with elevations at which $D$. ponderosae activity can regularly become attenuated by low temperatures [8]. Consequently, D. ponderosae attacks to P. contorta are seldom documented above $3000 \mathrm{~m}$ of elevation [8-10]. However, during the last epidemic, D. ponderosae attacks were observed above $3000 \mathrm{~m}$ providing the opportunity to study their activity in areas where they occur irregularly. While studying this in the Roosevelt National Forest in northern SRM in Colorado, red-elytra Dendroctonus beetles resembling D. murrayanae and D. rufipennis were attracted to baited (Exobrevicomin-Myrcene-Transverbenol, Synergy Semiochemicals) funnel traps (12-funnel Lindgren) monitoring D. ponderosae activity. Due to their resemblance and the response to D. ponderosae lures, that included one $P$. contorta tree component, these beetles were difficult to identify to species. Attacks by similar bark beetles were also documented in southern parts of the SRM in Colorado, where D. murrayanae has not been documented. On all occasions, these bark beetles were found in mixed stands of $P$. contorta with $P$. engelmannii. Thus, the question of whether it was D. murrayanae or D. rufipennis the species responsible for some of the attacks to P. contorta in the region's subalpine forests became a topic of relevance.

Dendroctonus rufipennis has been reported attacking $P$. contorta in the SRMs before, from 1944-1949 [11] and in 1957 [12] (Figure 1); however, a taxonomic authority [5,7] contradicted those determinations. The phenomena of D. rufipennis attacks to P. contorta in the SRM may be poorly understood due to the difficulty of separating it from $D$. murrayanae attacking that host in subalpine forests. In this study, Dendroctonus beetles attacking P. contorta in SRM' subalpine forests of Wyoming and Colorado were examined. The objectives of this study were to (1) improve the identification of adult Dendroctonus and the detection of their attack signs and patterns, (2) confirm the identity of Dendroctonus spp. with red-elytra attacking P. contorta in subalpine forest, and (3) discover new biological information about these Dendroctonus species.

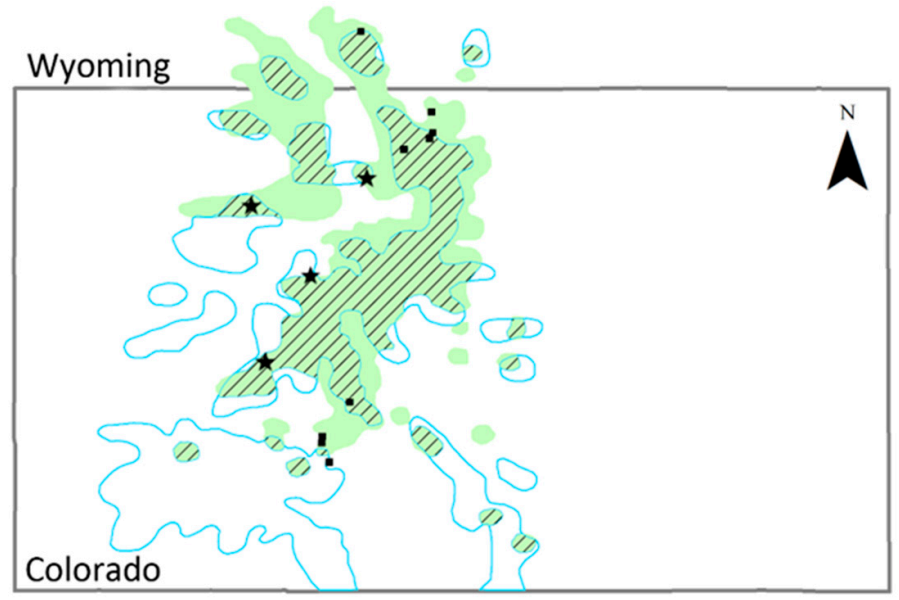

Figure 1. Southern Rocky Mountains sites were D. rufipennis was identified attacking P. contorta. Records from the 1940s and 1950s are indicated by stars, and squares indicate records made during this study. P. engelmannii (green) and P. contorta (blue) layers were modified from [13], trees intermix in the dashed areas. 


\section{Materials and Methods}

Sites in this study were in the SRMs, from southern Wyoming to southern Colorado (Figure 1). Yellowing trees in the spring or red ones in the fall with pitch tubes were used as evidence of trees infested by Dendroctonus beetles. In these areas, both live and dead adult beetles were collected. Live specimens were collected from live P. contorta as these attacked, while dead specimens were found trapped beneath the tree's bark and on the duff around the tree collar. Specimens were placed individually in $1.5 \mathrm{~mL}$ microcentrifuge tubes. In the laboratory, specimens were cleaned in an ultrasonic cleaner (100005, Sper Scientific) using warm water and mounted for examination. Previously determined diagnostic characters [5-7,14-17] were used to revise and determine the best diagnostic characters of collected specimens. Voucher specimens from the Hopkins Collection, Rocky Mountain Station, Fort Collins, CO, and collected from P. contorta included: $(\mathrm{n}=5)$ Rout N. F. (VII-48, Coll. Unk., No. 34220-L-6; $(\mathrm{n}=5)$ Yeoman Campground, White River N. F. (IX-1947-Coll. Wygant, No. 34220-L-7; ( $\mathrm{n}=4$ ) Trappers Lake, White River N. F. (VII-1946, Coll. C.J. Hay, No 31409-E; $(\mathrm{n}=2)$ Jumping Creek Campg., Helena, MT (Helena-Lewis and Clark N. F.) (VI-1989, Coll. J.B. Johnson, ID by Furniss), and collected from Pinus albicaulis (Whitebark pine) (Engelm.) in Wyoming: $(\mathrm{n}=10)$ Bridger-Teton N. F. (labeled Dubois) (VII-1936, Coll. J. A. Beal, No. 17700-M-1).

A subsample of red-elytra Dendroctonus from Colorado and Wyoming were selected to examine male genitalia. In these, sex was determined by examining a secondary sexual character, i.e., the granules in the interstriae declivity, which are greatly reduced (nearly absent) in males in contrast to being abundant in females $[7,14,15]$. Before dissecting, male beetles were softened in warm water for five minutes, after which the abdomen was removed ventrally by pulling it using a pair of forceps posteriorly to the metacoxae to access to the aedeagus. Removed aedeagi were cleared in a solution of $10 \% \mathrm{KOH}$ heated in a warm bath $\left(55^{\circ} \mathrm{C}\right)$ for $15 \mathrm{~min}$ to clear the sclerotized aedeagal capsule eliminating the need of removing the delicate endophallus [18] for its examination. Structures were examined with a Leica M16 stereomicroscope (Leica Microsystems, Castle Rock, CO, USA).

\section{Results}

\subsection{New Records of Dendroctonus spp. Attacking P. contorta in the Southern Rocky Mountains}

Previous reports of D. rufipennis attacking P. contorta in the SRM where from Routt N. F., Grand Mesa N. F., and White River N. F. limiting records to North-Central Colorado west of the Continental Divide. Dendroctonus rufipennis was here detected attacking numerous P. contorta in subalpine forests from Medicine Bow N. F. in southern Wyoming and from Roosevelt N. F., Gunnison N. F., and Rio Grande N. F. in Colorado encompassing the entire SRM's latitudinal range (Figure 1) and the east side of the mountain range. Dendroctonus rufipennis is evidently affecting a larger number of trees than in 1940 and 1957, where it was reported to affect 250 and 140 trees, respectively. These findings make the occurrence of this event more widespread and potentially more impactful than previously reported. Dendroctonus adjunctus Blandf. has never been reported before attacking P. contorta. Attacks of this species were detected on a single site in the Rio Grande N. F. where it was found attacking three P. contorta together with $D$. rufipennis; therefore, treatment of this species is limited in this manuscript.

\subsection{Diagnosing Dendroctonus Adult Beetles Attacking P. contorta in Subalpine Forest}

The external color of the three Dendroctonus is a simple starting point to separate D. ponderosae from the two red-elytra Dendroctonus. Adult $D$. ponderosae has an even thorax and elytra color, whereas most adult $D$. murrayanae and $D$. rufipennis have a darker thorax contrasting with their reddish elytra (Figure 2). Although D. adjunctus is also even colored, this species is unique among the four species in having a vertical impression on its mid-upper frons. However, these color differences alone are not useful to diagnose a fraction of older D. rufipennis and D. murrayanae that have black elytra matching their head and thorax. Color should be used in conjunction with the length of dorsal setae, particularly of that in the elytral declivity where the two red-elytra beetles have longer setae than D. ponderosae 
(Figure 2), these two characters are evident to the naked eye on clean specimens. Low magnifications $(<7 \mathrm{X})$ allow distinguishing the dull surface of the elytral declivity and the clearly impressed (flattened) second and third interstrial space that curve strongly towards the suture in D. ponderosae. This character distinguishes D. ponderosae from D. murrayanae and D. rufipennis and, as previously described [14,15], were referred to as striae II and III $[7,17]$.

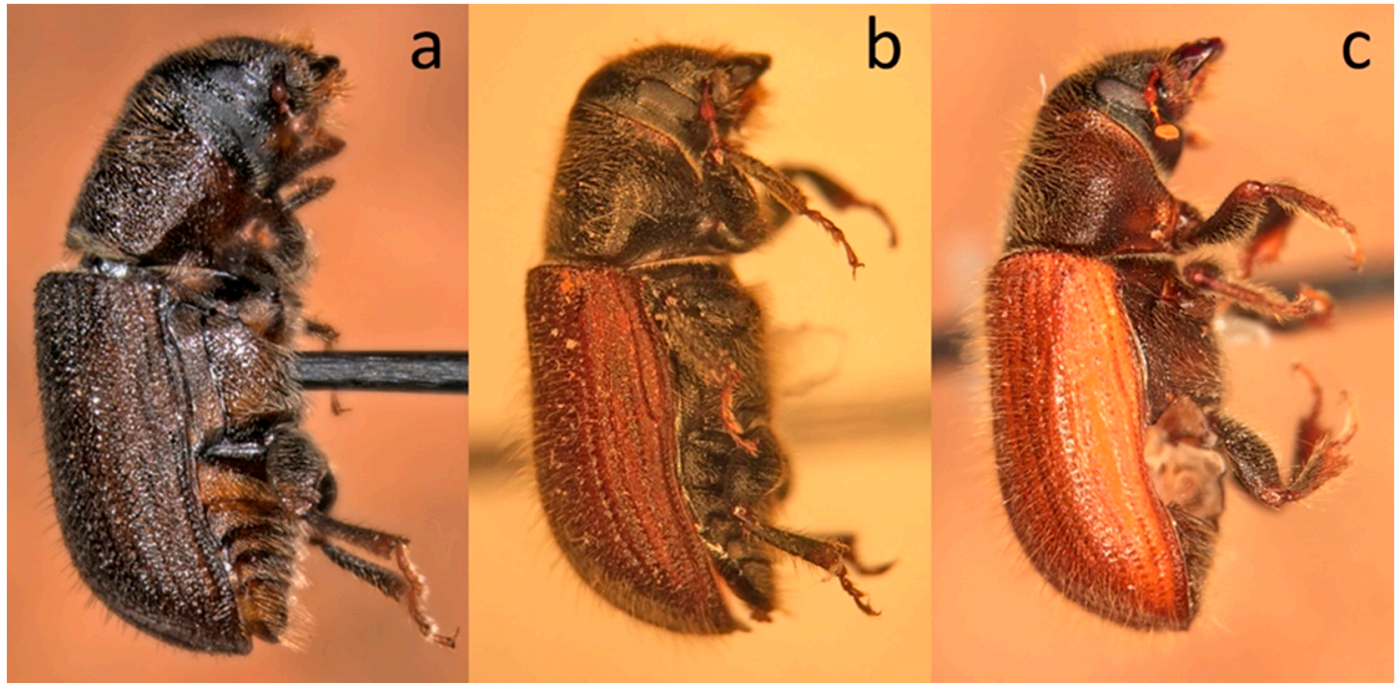

Figure 2. Three Dendroctonus bark beetles attacking P. contorta in the southern Rocky Mountains (SRM): (a) D. ponderosae distinguished from the other two by having equally colored thorax and elytra and shorter elytral declivity setae, (b) D. rufipennis examined in the SRM had duller exoskeletal surfaces than (c) D. murrayanae. Pictures by J. Mercado.

Whereas distinguishing $D$. ponderosae from the other two species was relatively easy, red-elytra species (i.e., D. murrayanae and D. rufipennis) are difficult to distinguish from each other. An early diagnostic character, the presence of punctures on the posterior half of the pre-episternal (synonyms: preëpisternal, proepisternal) area in D. murrayanae described as absent in D. rufipennis [14] (Figure 3) was examined. This morphological character proved to be confusing since (1) it was poorly defined, (2) its study requires the use of magnifications of 40X, and (3) punctures were present, but were more difficult to see in some D. rufipennis. Another character examined described by Wood [7], was the granules and punctures in the frons. He mentioned that "the relative number of punctures and granules offer the only reliable method of separating D. murrayanae from D. rufipennis."

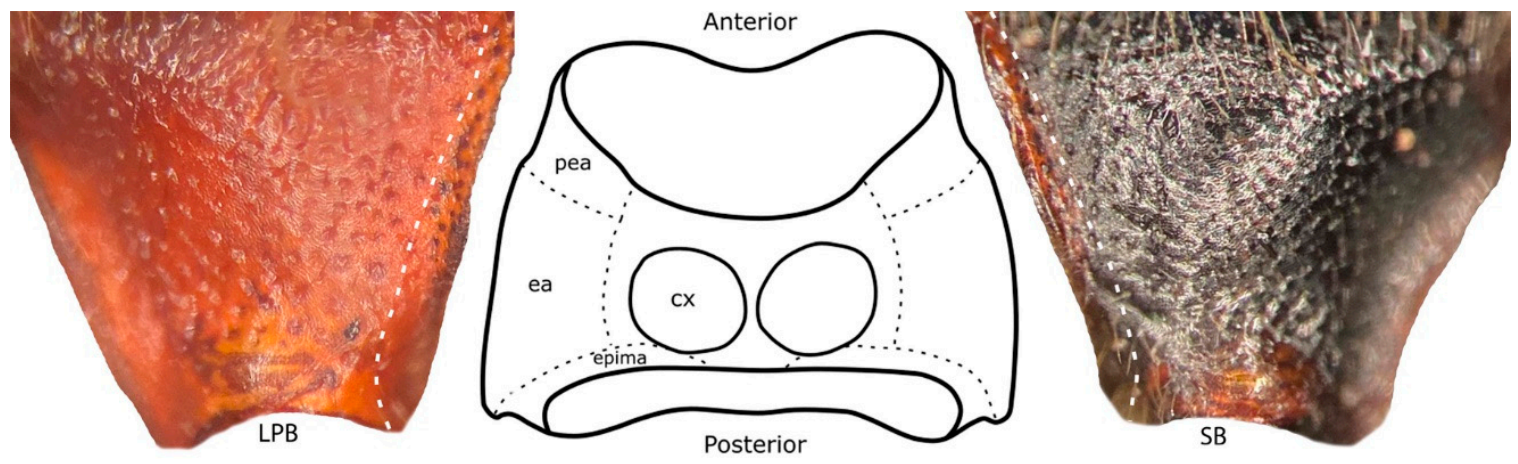

Figure 3. From anterior to posterior, the sides of a Dendroctonus thorax is divided into three areas [14]: (1), pre-episternal (pea), (2) episternal (ea), and (3) epimeral (epima). The character of the relative number of punctures at the posterior half of (pea) near white dashed lines, to distinguish D. murrayanae from D. rufipennis is difficult to use. Pictures by J. Mercado, thorax line drawing adapted from Hopkins [14]. 
The exoskeletal surfaces of Dendroctonus beetles, including the frons, are covered by semi-circular impressions called punctures, and by blunt cusps called granules, the number of these is never quantified, but puncture closeness and granule location and their spread are described between similar species. In both D. murrayanae and D. rufipennis, punctures are described as being very close; however, in the center of the frons (between the compound eyes), these are described as "distinct" in D. murrayanae and "largely obliterated" in D. rufipennis [5,7].

Wood [5,7] described that granules in the frons interpuncture space are more clearly separated or "isolated" in D. murrayanae than in D. rufipennis "coarsely granulate," but in this study granules were found isolated and dispersed in D. rufipennis as well. This study found that interpuncture space surfaces in D. rufipennis are usually rougher, making granules and punctures hard to discern, whereas these are usually smoother on D. murrayanae, making granules and punctures more apparent, especially in the middle of the frons. This character was found to be useful separating most D. rufipennis and D. murrayanae specimens, but some D. rufipennis had distinct mid-frons punctures; therefore, its use is recommended in addition to other characters. The smoother interspaces also helped to distinguish most D. murrayanae from D. rufipennis when examining other exoskeletal surfaces dorsally and laterally, such as elytra (Figure 2), from similar angles and at similar magnification. At low magnification (7.1X), examined D. murrayanae specimens in collection boxes appear glossier than those of D. rufipennis (Figure 2). It is recommended that the state of rough vs. smooth to describe the frons interpuncture space surface in the frons center is examined to help separate these species. The accuracy of this character should be studied further for specimens outside the SRM. A new diagnostic character found in this study was simple to use and works with the examined female D. rufipennis and D. murrayanae specimens. There is a sharp deflection of striae III away from the suture near striae IV and then towards the suture near striae VI in D. rufipennis. This deflection is present in D. murrayanae but it is smooth, making it less distinct (Figure 4). As described, the character was consistently present on all examined female specimens but not easily seen in some males, and its use in other regions merits further study. In males, or when the above characters are obscure or missing on a specimen in poor condition, the character to examine is the distinctly different endophallus [7] of D. rufipennis and D. murrayanae (Figure 5).

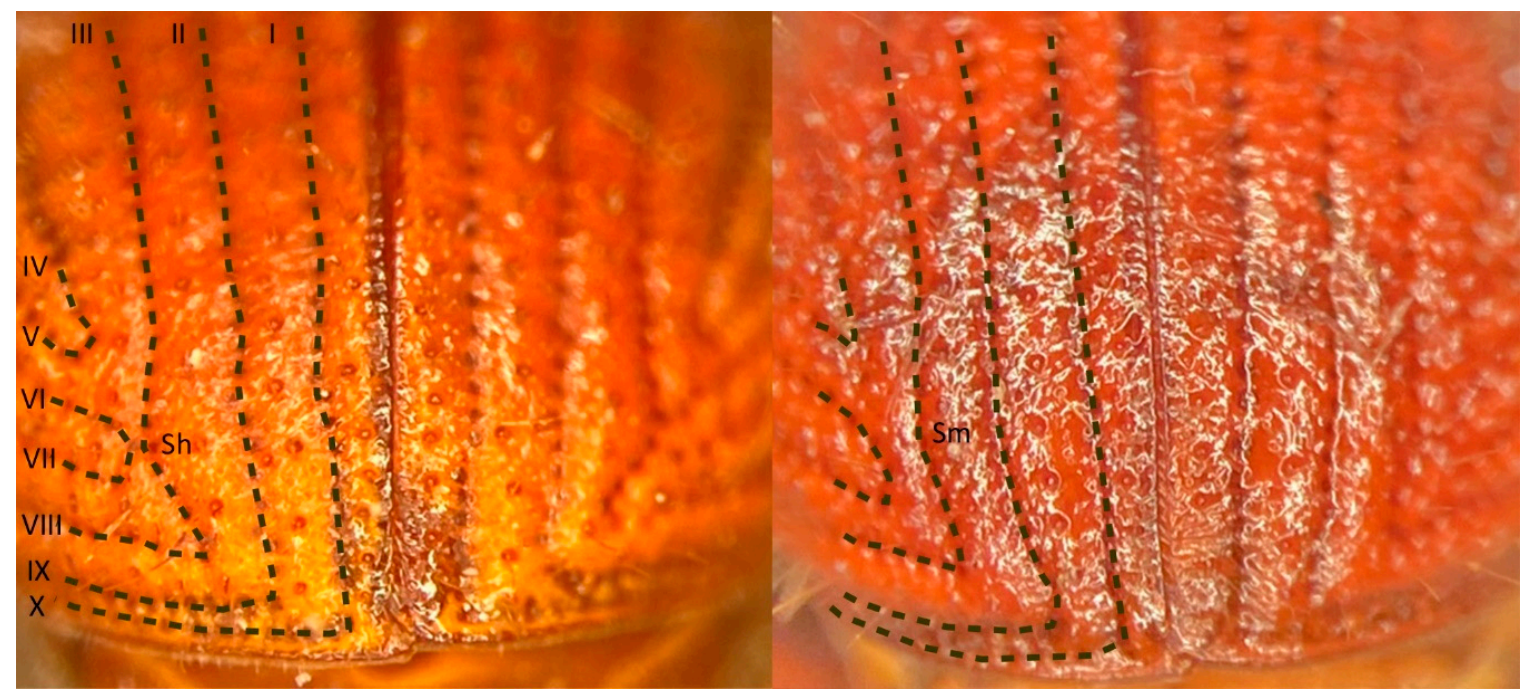

Figure 4. The striae (dashes) and interstriae in the declivity of D. rufipennis (left) and D. murrayanae (right). Striae III curves sharply (Sh) towards the suture opposite to striae VI in D. rufipennis, but smoothly (Sm) in D. murrayanae. Photos by J. Mercado. 


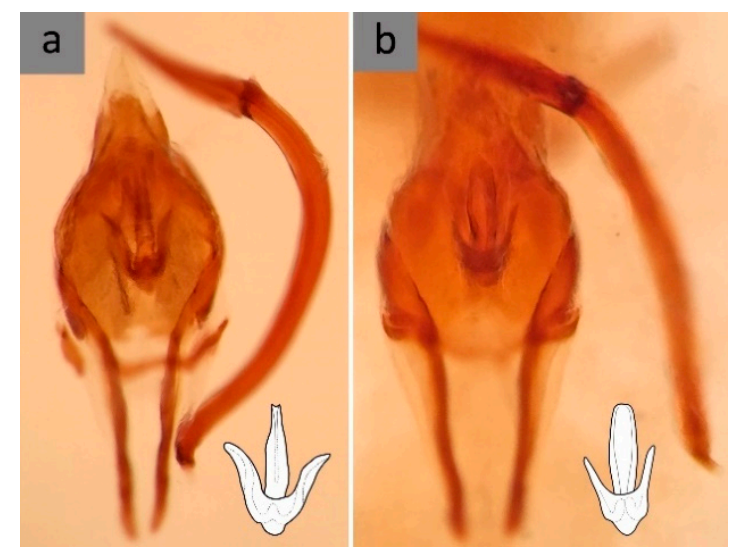

Figure 5. The male genital capsule of D. rufipennis (a) and D. murrayanae (b). An internal structure in the genital capsule, the endophallus, is seen through the median lobe (also inserts lower right corners). The endophallus is diagnostic for the two species when other means have been exhausted. Photos by J. Mercado. Endophallus line drawings adapted from Wood [7].

To improve diagnosing adult beetles of the similar red-elytra D. murrayanae and D. rufipennis attacking P. contorta in the SRM, the use of the simplified and improved couplet below is recommended.

Mid-frons punctures distinct; frons and elytra interpuncture spaces smooth; (females, difficult on males) declivity striae III turning sharply (angled) towards suture, opposite to striae VI; (males) genitalia distinctive. D. murrayanae Hopk.

Mid-frons punctures usually obscure; frons and elytra interpuncture spaces usually rough (rugose, granulate); (females, difficult on males) declivity striae III turning smoothly (arched) towards suture, opposite to striae VI; (males) genitalia distinctive. D. rufipennis (Kirby).

\subsection{Diagnosing Dendroctonus Attacks Characteristics to Subalpine P. contorta}

Separating D. rufipennis from D. murrayanae using only morphology is difficult; therefore, to complement adult insect determinations, available behavioral characteristics were reviewed, and a new helpful alternative is presented. These are also helpful in the absence of adult insects. The period and height from the duff of tree attack by the three Dendroctonus species are useful to identify the species. Reddish elytra Dendroctonus (i.e., D. murrayanae and D. rufipennis) attack earlier (June), whereas D. ponderosae attacks later (July and August). In the fall, D. rufipennis move to the lower $60 \mathrm{~cm}$ of the tree to overwinter [5], this is the area were D. murrayanae develops, making male genitalia examination needed for accurate species determination at that time. In June, attacks of D. rufipennis and D. murrayanae can be determined by the height at which they attack the tree. Attacks above $60 \mathrm{~cm}$ are made solely by $D$. rufipennis, while the attacks of $D$. murrayanae concentrate below that, but especially below $20 \mathrm{~cm}$ [6]. In July and August, both D. ponderosae and D. rufipennis attack above $60 \mathrm{~cm}$, this requires examining other traits in late August to confirm the attacking insect.

Although Wood [7] suggested pitch tubes could be used to identify the attack of Dendroctonus species, he did not describe them in his monograph of the genus Dendroctonus. The examination of the pitch tubes of beetles attacking above $60 \mathrm{~cm}$ made in July and August is recommended here. Pitch tubes that sometimes form a slide on the lower outer border are characteristic of D. rufipennis (Figure 6). A few days after the attack, these become bulkier than those of $D$. ponderosae attacking the same tree, which differ as they resemble a perpendicular chimney (Figure 6). The characteristic sign was tested by predicting whether $D$. ponderosae or $D$. rufipennis was the attacking beetle. Out of 26 specimens collected with a chimney type pitch tube present, $58 \%$ were $D$. ponderosae (Table 1 ). In specimens collected with a slide/bulge-type pitch tube, all were $D$. rufipennis. The low accuracy predicting $D$. ponderosae did not occur due to confusion with $D$. rufipennis but with $D$. adjunctus, performing undocumented attacks in P. contorta in southern Colorado. It is important to note that soft, sappy pitch tubes that somewhat 
resemble a slide can be made by D. ponderosae attacking P. contorta at lower elevation forests. This occurs when irruptive populations attack healthy trees with a strong quantitative oleoresin response, but a clear slide is not made by $D$. ponderosae. This should be used as the first step before verifying the insect and egg gallery and only in subalpine P. contorta/P. engelmannii forest type.

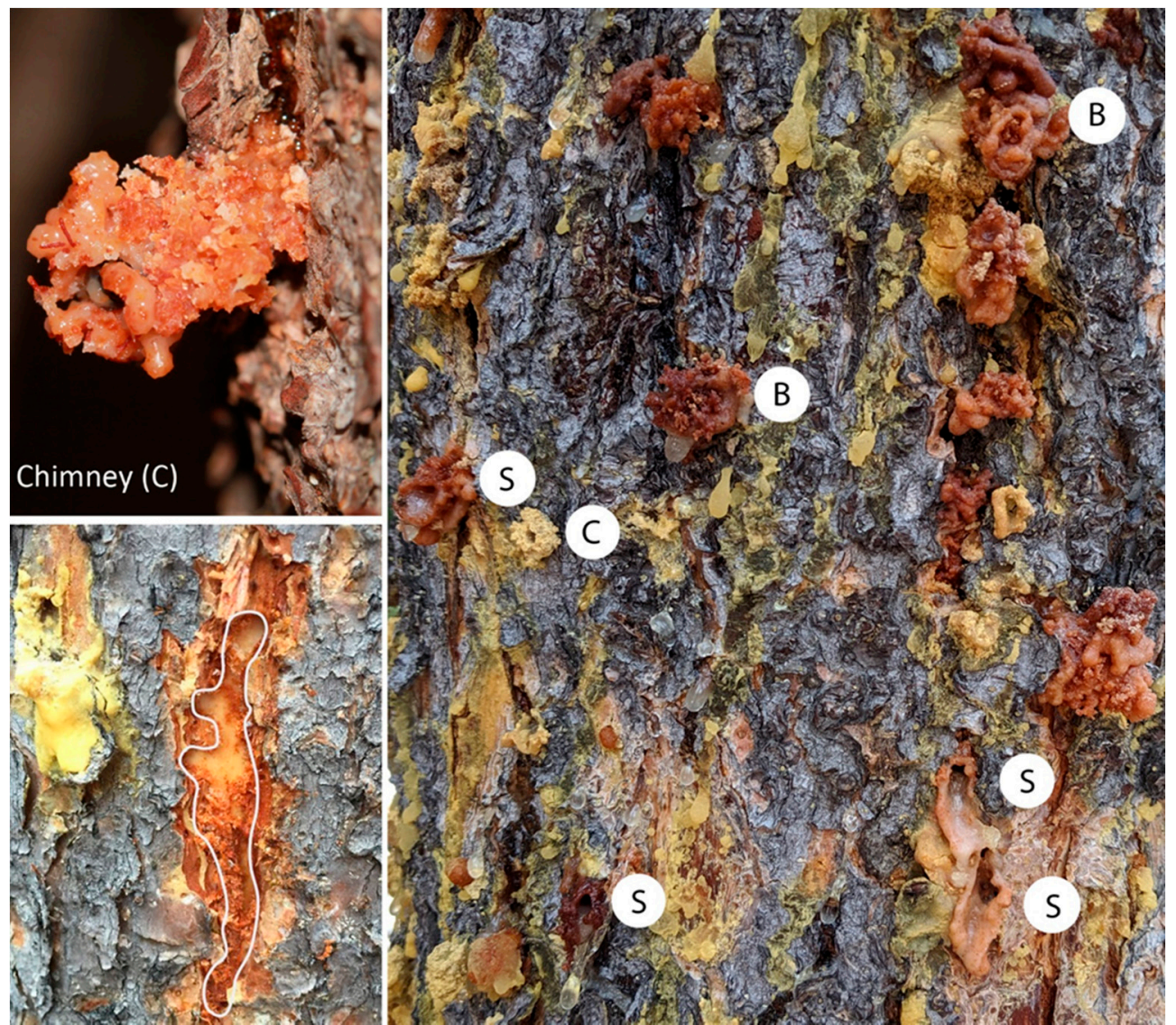

Figure 6. Distinguishing characteristics of Dendroctonus attacks to P. contorta in the southern Rocky Mountain subalpine forest include the shape of their pitch tubes and the length of their galleries. Clockwise from top left: (1) the chimney-like pitch tube of $D$. ponderosae is perpendicular to the tree with a near round outer border, (2) a mix of different pitch tube shapes with bulky (B) and slide-forming ones (S) by D. rufipennis and a chimney-shaped one (C) made by D. ponderosae, and (3) the turning notches in the short D. rufipennis egg gallery. Photos by J. Mercado.

Table 1. Quantified characters of Dendroctonus spp. bark beetles attacking subalpine P. contorta in the SRM during this study. Note: D. murrayanae Hopk. adults or their attacks were not found during this study.

\begin{tabular}{cccccccc}
\hline & \multicolumn{2}{c}{ Attack Height } & \multicolumn{2}{c}{ Pitch Tube Type } & \multicolumn{2}{c}{ Egg Gallery Length } \\
\hline Dendroctonus sp. & $<20 \mathrm{~cm}$ & $60-150 \mathrm{~cm}$ & chimney & slide/bulge & $<13 \mathrm{~cm}$ & $>23 \mathrm{~cm}$ & Total \\
D. adjunctus Blandf. & 0 of 11 & 11 of 11 & 11 of 11 & 0 of 11 & 0 of 11 & 11 of 11 & 11 \\
D. ponderosae Hopk. & 0 of 16 & 16 of 16 & 15 of 16 & 1 of 16 & 0 of 16 & 16 of 16 & 16 \\
D. rufipennis (Kirby) & 0 of 75 & 75 of 75 & 0 of 75 & 75 of 75 & 78 of 75 & 0 of 75 & 75 \\
\hline
\end{tabular}

Second, the identification accuracy of beetle attacks made above $60 \mathrm{~cm}$ increased by examining the length of egg galleries $(\mathrm{n}=102)$. Dendroctonus rufipennis egg galleries averaged $13 \mathrm{~cm}$, whereas those of $D$. ponderosae were longer than $23 \mathrm{~cm}$, as previously described [5]. In the sampled egg galleries, $59.2 \%$ of these measuring over $16 \mathrm{~cm}$ in length corresponded to $D$. ponderosae $(\mathrm{n}=16)$, and no D. rufipennis egg gallery measured over that. Moreover, 11 of the 27 long galleries studied were made by $D$. adjunctus, making this character useful for separating these two species from $D$. rufipennis in 
southern Colorado, although not from D. ponderosae. Dendroctonus rufipennis galleries also have short spurs on the sides along their short length that are used as turning sites for the adult beetle, which are absent in D. ponderosae egg galleries (Figure 6).

3.4. Documentation of D. rufipennis Reproduction in Live P. contorta and Verification of Museum Specimens from the 1940's Report of D. rufipennis Attacking That Host

The complete development of D. rufipennis adults in P. contorta was first suspected in 2014 from the collections of teneral adults from under the bark in Gunnison N. F. in southern Colorado, and in Medicine Bow N. F. in southern Wyoming where these were again collected from the same tree in July 2015 when a dead pupa was found. In mid-July of 2016, standing, live P. contorta in northern Colorado contained 12 D. rufipennis adults initiating galleries - three of which had laid eggs, which confirmed reproduction initiation attempts by the species. In about the same date, adults $D$. rufipennis were seen emerging a $P$. contorta in the Medicine Bow N. F. and simultaneously a P. contorta located $10 \mathrm{~m}$ from it was being attacked by $D$. rufipennis. Since there were no other trees with activity within a $30 \mathrm{~m}$ radius from these two trees, re-attack to P. contorta by D. rufipennis in that forest is suspected. As eggs, pupae, and teneral adults have been found under the bark of $P$. contorta reproduction in this host is considered confirmed from the SRM P. contorta/P. engelmannii subalpine forest.

Red-elytra Dendroctonus specimens collected from the 1940's D. rufipennis epidemic in Colorado (Wygant, White River N. F., 1947), were examined. These beetle specimens resembled D. murrayanae in their color pattern, but the examination of the male genitalia confirmed specimens represented D. rufipennis, confirming their prior attack to P. contorta in SRM.

\section{Discussion}

Although, previous reports of D. rufipennis attacking P. contorta in the SRM exist, there remained uncertainty about their veracity. As discussed in his review of the genus Dendroctonus, Wood [7] examined some of the red-elytra Dendroctonus specimens reported attacking P. contorta in the 1940 s. On all suspected cases of D. rufipennis attacks to $P$. contorta, he determined that the insect involved was D. murrayanae [5,7]. However, it is unclear whether the specimens he studied were the same that Massey and Wygant [11] had determined to be D. rufipennis [19]. An issue with Massey and Wygant [11] is that they only report using the characters described by Hopkins [14] to diagnose D. rufipennis from D. murrayanae. These characters were considered insufficient to separate these species by Wood [7] without studying the male genitalia (endophallus). This insufficiency was confirmed in this study as well, as all red-elytra beetle examined from 2010 to 2016 were incorrectly identified as D. murrayanae using the key in [14].

Although it is possible Massey and Wygant [11] knew of an effective way to separate the two red-elytra Dendroctonus, this was not effectively expressed in their report. Therefore, characters and keys referred by them should only be used by expert taxonomists of this group of beetles and even then, with great care and understanding of their limitations. Consistently with Wood [7], it is recommended that careful examination of the male' endophallus is used as the best approach to separate these two species when using adult morphology alone, especially when the newly described elytral striae number three character is confusing or missing. However, apart from the endophallus only we found that Wood's [5,7] key couplet describing the clarity of the punctures on the frons center offered diagnostic utility.

There are still questions regarding the activity of Dendroctonus bark beetles in subalpine P. contorta/ P. engelmannii forest across their distribution. First, why is D. rufipennis attacking this nonhost in the SRMs? Schmid and Frye [19] suggested that under outbreak conditions, Dendroctonus species can attack nontypical hosts in the absence of suitable primary hosts. In other forests where P. contorta and P. engelmannii intermix, D. ponderosae has opportunistically attacked and developed in P. engelmannii [20] or the hybrid Picea engelmannii $\times$ glauca [21]. Attacks by single D. ponderosae pairs to P. engelmannii were also observed near one of this study' sites in northern Colorado. However, there were suitable 
hosts in the vicinity of both Dendroctonus species attacking nonhosts in Colorado. The nonhost attack in subalpine P. contorta/P. engelmannii forest type by D. rufipennis may be possible due to the following factors: (1) irruptive populations of both species can occur simultaneously in areas were their hosts grow intermixed, confusing the insects' olfactory response, (2) a similar tree volatile is produced by stressed trees of both species, i.e., $\alpha$-pinene, and/or (3) even in trees previously attacked by D. ponderosae, D. rufipennis is not rejected by any of the semiochemicals released by that species.

Also questioned is whether has the activity of D. rufipennis in subalpine P. contorta been overlooked or confused? This is difficult to answer, but the author's experience and discrepancies in previous reports suggest $[5,7,11]$ this is possible. Here, guidelines are provided to help elucidate this, and ongoing research by the author is measuring the impacts of this activity in the SRM. Among others, is there a biological function of non-host attacks by bark beetles? One possible function that merits further investigation is the potential of reciprocal facilitation of multiple Dendroctonus species attacks to both species. It has been suggested that "primary bark beetles", those that attack primarily live and apparent healthy trees, survive in their endemic state by becoming "secondary bark beetles" — that is, attacking trees that have been previously attacked by other bark beetles or are otherwise compromised [22]. This has been suggested for $D$. ponderosae attacking high latitude/elevation $P$. contorta that had been previously attacked by Ips mexicanus bark beetles in Canada [23]. Thus, the study of facilitation for these two co-attacking species is merited. An outcome of facilitation may be the reproduction of a nonhost attacker that, at the same time, benefits the reproductive success of the native host attacker when occurring in its endemic state. This needs to be studied in the SRM with D. ponderosae and D. rufipennis.

The successful reproduction of D. rufipennis has been found in laboratory experiments in BC, Canada, where no developmental differences were noted for D. rufipennis raised in P. contorta or in white-P. engelmannii hybrid bolts of these species [24]. Live P. contorta, however, may be more able to defend against D. rufipennis attacks, as suggested by hundreds of D. rufipennis found dead around the base of attacked trees compared to only a handful D. ponderosae throughout the surveyed years. However, the cumulative D. rufipennis attacks attempts and the pheromones they release combined with the defensive tree compounds released in their response may elicit an olfactory signal attracting D. ponderosae. This may facilitate the attack of that species first, and potentially that of $D$. rufipennis later by reducing the defense capacity of trees attacked by its primary insect enemy. This may represent an ecological adaptation supporting endemic populations of both species in this high-elevation forest. Here, eggs and teneral (immature) adults of D. rufipennis in P. contorta are documented in trees containing a few $D$. ponderosae attacks, arguably providing a starting point towards establishing this hypothesis. However, there is a need to better measure reproductive success in this host as well as the tree conditions permitting its attack.

\section{Conclusions}

Useful guidelines for the accurate determination of Dendroctonus species attacking P. contorta in subalpine forest in the SRM are presented. The approach uses behavioral and morphological characters to provide an undemanding method for determining even the poorly documented attack to $P$. contorta by D. rufipennis. All red-elytra Dendroctonus bark beetles found attacking $P$. contorta in this study were $D$. rufipennis. This does not mean that D. murrayanae is absent from the SRM, but it reflects our sampling from $50 \mathrm{~cm}$ to $2 \mathrm{~m}$ above the collar and perhaps the rarity of the species in the SRMs. The attacks to $P$. contorta in subalpine forest by nontypical Dendroctonus are either poorly reported due to difficulties identifying these Dendroctonus and/or on the rise in response to current climate variations. Simplifying the diagnostics of these species is a necessary step and provides the tool for improving our knowledge about bark beetle disturbances in subalpine ecosystems. In the absence of adult male beetles, characteristics of their attack in combination with careful examination of the morphological characters as summarized here can help elucidate the attacking species. 
Funding: This research received no external funding.

Acknowledgments: This study is dedicated to Sheryll Costello ${ }^{\dagger}$. Sheryl was an avid entomologist working with USDA Forest Health and Protection, whose passion for forest entomology was inspirational. Sheryl passed while pursuing her outdoor adventures; she is remembered. Many thanks to Tom Eager (FHP, Washington) for providing specimens from the Gunnison N. F. and for asking some of the initial questions that were further developed in this study. Also, to Jeff Witcosky ${ }^{1}$ ( ${ }^{1}$ retired USDA Forest health and Protection) and Sheryl Costello for providing details about attacks of D. rufipennis to P. contorta in the SRM. Thanks to Osiris Valerio (Instituto Politécnico Nacional, Mexico) and Donald Bright (Colorado State University) for their demonstrations of dissection techniques and their enriching conversations; and to Robert Hubbard, José F. Negrón, and Shannon Kay (RMRS, Fort Collins) for their review and comments on earlier versions of the manuscript. ${ }^{\dagger}$ (1977-2011).

Conflicts of Interest: The author declares no conflict of interest.

\section{References}

1. Peet, R.K. Forest vegetation of the Colorado front range. Vegetatio 1981, 45, 3-75. [CrossRef]

2. Klutsch, J.; Negron, J.F.; Costello, S.L.; Rhoades, C.C.; West, D.R.; Popp, J.; Caissie, R. Stand characteristics and downed woody debris accumulations associated with a mountain pine beetle (Dendroctonus ponderosae Hopkins) outbreak in Colorado. For. Ecol. Manag. 2009, 258, 641-649. [CrossRef]

3. Meddens, A.J.; Hicke, J.A. Spatial and temporal patterns of Landsat-based detection of tree mortality caused by a mountain pine beetle outbreak in Colorado, USA. For. Ecol. Manag. 2014, 322, 78-88. [CrossRef]

4. Forest Insect and Disease Conditions in the Rocky Mountain Region 2005. Available online: https: //www.fs.usda.gov/Internet/FSE_DOCUMENTS/stelprdb5279149.pdf (accessed on 1 December 2016).

5. Wood, S.L. The Bark and Ambrosia Beetles of North and Central America (Coleoptera: Scolytidae), a Taxonomic Monograph, Great Basin Naturalist Memoirs, No. 6; Brigham Young University: Provo, UT, USA, 1982; pp. 150-203. [CrossRef]

6. Furniss, M.M.; Kegley, S.J. Biology of Dendroctonus murrayanae (Coleoptera: Curculionidae: Scolytinae) in Idaho and Montana and comparative taxonomic notes. Ann. Entomol. Soc. Am. 2008, 101, 1010-1016. [CrossRef]

7. Wood, S.L. A revision of the bark beetle genus Dendroctonus Erichson (Coleoptera: Scolytidae). Great Basin Nat. 1963, 23, 1-117. [CrossRef]

8. Amman, G.D.; Baker, B.H.; Stipe, L.E. Lodgepole Pine Losses to Mountain Pine Beetle Related to Elevation, Research Note INT-171; USDA/FS, Intermountain Forest \& Range Exp. Sta.: Ogden, UT, USA, 1973; pp. 1-8.

9. DeLeon, D. The Biology and Control of the Black Hills Beetle (Dendroctonus ponderosae Hopk.), Summary of Studies in Colorado and Wyoming (1935-1938), Report to the Forest Insect Laboratory (Unpublished); USDA/FS: Fort Collins, CO, USA, 1939.

10. Mitton, J.B.; Ferrenberg, S.M. Mountain pine beetle develops an unprecedented summer generation in response to climate warming. Am. Nat. 2012, 179, E163-E171. [CrossRef] [PubMed]

11. Massey, C.L.; Wygant, N.D. Biology and Control of the Engelmann Spruce Beetle in Colorado, Circular No. 944; USDA/FS: Washington, DC, USA, 1954; pp. 1-35.

12. McCambridge, W.F.; Knight, F.B. Factors affecting spruce beetles during a small outbreak. Ecology 1972, 53, 830-839. [CrossRef]

13. USGS Digital Representations of Tree Species Range Maps from "Atlas of United States trees" by Elbert, L. Little, Jr. (and Other Publications). Available online: https://gec.cr.usgs.gov/data/little/ (accessed on 15 December 2016).

14. Hopkins, A.D. Contributions Toward a Monograph of the Scolytid Beetles, Tech. Ser. 17, Part I: The genus Dendroctonus; USDA Bureau of Ent.: Washington, DC, USA, 1909; pp. 1-164.

15. Hopkins, A.D. Practical Information on the Scolytid Beetles of North American Forests, Bull. 83, Part I: Bark Beetles of the Genus Dendroctonus; USDA Bureau of Ent.: Washington, DC, USA, 1909; pp. 1-169.

16. Swaine, J.M. Canadian Bark Beetles, Part II. Preliminary Classification, with an Account of the Habits and Means of Control, Bulletin 14; Department of Agriculture: Ottawa, ON, Canada, 1918.

17. Bright, D.E., Jr. The Insects and Arachnids of Canada, Part 2: The Bark Beetles of Canada and Alaska, Coleoptera: Scolytidae; Canada Department of Agriculture: Ontario, ON, Canada, 1976; pp. 1-241.

18. Hopkins, A.D. Contributions toward a Monograph of the Scolytid Beetles, Part II: Preliminary Classification of the Superfamily Scolytoidea, Tech. Ser. 17; USDA Bureau of Ent.: Washington, DC, USA, 1915; pp. 1-232. 
19. Schmid, J.; Frye, R. Spruce Beetle in the Rockies, Gen. Tech. Report RM-49; USDA/FS, Rocky Mountain Forest and Range Exp. Sta.: Fort Collins, CO, USA, 1977; pp. 1-38.

20. Amman, G.D.; Cole, W.E. Mountain Pine Beetle Dynamics in Lodgepole Pine Forests. Part II: Population Dynamics, Gen. Tech. Report INT-145; USDA/FS, Intermountain Forest and Range Exp. Sta.: Ogden, UT, USA, 1983; pp. 1-59.

21. Huber, D.P.; Aukema, B.H.; Hodgkinson, R.S.; Lindgren, B.S. Successful colonization, reproduction, and new generation emergence in live interior hybrid spruce Picea engelmannii $\times$ glauca by mountain pine beetle Dendroctonus ponderosae. Agric. For. Entomol. 2009, 11, 83-89. [CrossRef]

22. Koopmans, J.M. Spatial and temporal analyses of bark beetle population dynamics in southern British Columbia: Stand-level studies of the bole-infesting assemblage during eruptive transitions of mountain pine beetle, Dendroctonus ponderosae Hopkins. Master's Thesis, M.Sc., University of Northern British Columbia, British Columbia, Canada, 2008.

23. Smith, G.D.; Carroll, A.L.; Lindgren, B.S. Facilitation in bark beetles: Endemic mountain pine beetle gets a helping hand. Agric. Forest Entomol. 2011, 13, 37-43. [CrossRef]

24. Safranyik, L.; Linton, D.A. Brood production by three spp. of Dendroctonus (Coleoptera: Scolytidae) in bolts from host and non-host trees. J. Entomol. Soc. B. C. 1983, 80, 10-13.

(C) 2020 by the author. Licensee MDPI, Basel, Switzerland. This article is an open access article distributed under the terms and conditions of the Creative Commons Attribution (CC BY) license (http://creativecommons.org/licenses/by/4.0/). 